\title{
INCLUSÃO DE NOÇÕES DE DIREITO BÁSICO NO ENSINO MÉDIO
}

\author{
INCLUSION OF BASIC LAW NOTIONS IN HIGH SCHOOL
}

\author{
Josino Paulino Neto ${ }^{1}$ \\ Maira Regina de Carvalho Alexandre ${ }^{2}$
}

RESUMO: O presente trabalho aborda o acesso à educação. Nessa linha, propondo a possibilidade de inclusão do ensino jurídico na grade curricular do nível médio, partindo do direito à educação assegurado pelo ordenamento jurídico brasileiro que viabiliza um ensino mais complexo e dinâmico, além de habituar os alunos a noções de matérias que são essenciais para o convívio social. Somado a isso, um bom saber sobre o direito é um meio para se chegar à justiça, e nessa perspectiva, enquadra-se nos moldes da proposta de se incluir noções básicas de direito na grade curricular de ensino, que se apresenta como adequada, expressiva e essencial, pois a instrução jurídica, tem como objetivo mesmo que em um nível básico, o exercício da cidadania, além de contribuir para o desenvolvimento intelectual dos estudantes de forma extensiva e antecipada aos níveis de graduação. Desse modo, a metodologia de adaptação educacional de matérias bases do direito supririam aspectos expressivos na reeducação dos jovens brasileiros. Tarefa à qual, se dividiria em selecionar as áreas jurídicas que mais beneficiaria a instituição, além de debates e avaliações de desenvolvimento educacional.Por fim, o intuito da instrução jurídica pela implementação de matérias na grade curricular não se limitaria aos parâmetros educacionais, mas se estenderia a sociedade de uma forma abrangente, uma vez que a adaptação do projeto tornaria os cidadãos mais habituados aos conhecimentos jurídicos disseminando essa ideologia de uma forma indireta.

Palavras-chaves: Educação. Ensino Jurídico. Implementação.

ABSTRACT: This work addresses access to education. In this line, proposing the possibility of including legal education in the high school curriculum, based on the right to education guaranteed by the Brazilian legal system, which enables a more complex and dynamic teaching, in addition to accustoming students to notions of subjects that are essential for social life. In addition, a good knowledge of the law is a means to reach justice, and in this perspective, it fits the model of the proposal to include basic notions of law in the curriculum of teaching, which is presented as adequate, expressive It is essential, since legal instruction has the objective, even at a basic level, of exercising

\footnotetext{
${ }^{\mathrm{I}}$ Graduando em Direito pela UNITINS.

2 Mestra em Prestação Jurisdicional e Direitos Humanos (PPGPJDH), pela Universidade Federal do Tocantins (UFT). Professora da Graduação em Direito e Coordenadora do Núcleo de Prática Jurídica da Universidade Estadual do Tocantins (UNITINS) Campus de Augustinópolis. Advogada. Currículo Lattes: http://lattes.cnpq.br/o241426848139231. ORCID: https://orcid.org/oooo-0003-1533-9026. E-mail:
} mairareginazorı@gmail.com. 
citizenship, in addition to contributing to the intellectual development of students in an extensive and anticipated manner at undergraduate levels. In this way, the methodology of educational adaptation of basic subjects of law would supply expressive aspects in the re-education of young Brazilians. Task to which, it would be divided in selecting the legal areas that would most benefit the institution, in addition to debates and evaluations of educational development. Finally, the purpose of legal instruction for the implementation of subjects in the curriculum would not be limited to educational parameters, but would extend society broadly, since the adaptation of the project would make citizens more accustomed to legal knowledge by disseminating this ideology in an indirect way.

Keywords: Education. Legal Education. Implementation.

\section{INTRODUÇÃO}

Este trabalho faz referência a inclusão de ensino jurídica em níveis de educação básica. A relevância da presente pesquisa compreende a sua conveniência na proposta de inclusão que se defende sob o contexto jurídico e social.

O acesso às informações jurídicas é de vital importância para o cidadão. De modo, que o estado (na figura do juiz) não permite alegar desconhecimento da lei após transcorrido o tempo de vacatio legis, haja vista que, quando uma norma é legalmente positivada no ordenamento jurídico, é ou deveria, de fato ser do conhecimento de todos pois foi publicada no diário oficial, em contrapartida seu alcance só é almejado após algum impacto social devido a limitação na cultura educacional sobre conhecimentos jurídicos.

Nesse contexto, a pesquisa trabalha com a problematização que envolve um dos seguintes questionamentos: "seria ideal inserir disciplinas de direito básico na grade curricular do ensino médio?”. Ademais, por circunstâncias econômicas, culturais, religiosas entre outros, qual seria o conjunto de conhecimentos adequados, uma vez que são diversos ramos jurídicos e cada um com sua devida relevância.

Soma a isso, apesar de já manifestados artigos, projetos universitários, implementações de Ensino a Distância (EAD) feita pelo IFRS-Instituto Federal do Rio Grande do Sul, do curso técnico em serviços jurídicos do Instituto Federal do ParanáIFPR além da proposta no Congresso Nacional, da Lei do Senado no 70 de 2015, de autoria do Senador Romário, que propõe alteração dos artigos 32 e 36 da Lei no 9.394/96 (Lei de Diretrizes e Bases da Educação Nacional - LDB), para a inclusão da disciplina "Constitucional" nos ensinos fundamental e médio, hodiernamente não temos nenhuma 
referência educacional definitiva do que pode ser definido explicitamente quais são os direitos básicos e quais são implementáveis a grade curricular no ensino médio.

Para tanto, o trabalho tomará o viés de identificar os princípios, objetivos e as diretrizes que regem a educação no Brasil e demonstrar que tais aspectos se enquadram na implementação das matérias de direito básico. Em paralelo a isso,-apresentará ideologias educacionais na escolha dos cursos técnicos e destacar que a possibilidade de implementação dos conteúdos jurídicos se adequa com formação cidadã na Educação Básica. Por fim, demonstrar os apontamentos conclusivos de instituições que já adotam essa implementação.

De forma mais específica, pretende-se analisar a relevância da educação jurídica em um público de ensino básico, mostrar suas relevâncias e de qual forma poderá "reeducar" a cultura social na busca a justiça e qualificação profissional, além de discorre sobre as matérias básicas de Direito que poderão ser levadas aos estudantes do ensino regular.

\section{AMPARO CONSTITUCIONAL À EDUCAÇÃO}

A educação sendo direito de todos e obrigação do estado e da família está assegurado constitucionalmente (Constituição Federal, 1988)

Art. 205. A educação, direito de todos e dever do Estado e da família, será promovida e incentivada com a colaboração da sociedade, visando ao pleno desenvolvimento da pessoa, seu preparo para o exercício da cidadania e sua qualificação para o trabalho.

O Estado concebe a escola como instituição de ensino a qual, através de uma vasta grade curricular, está incumbida da formação plena do educando, na qual uma das finalidades é o exercício da cidadania citado pela Lei de Diretrizes e Bases do Ensino Nacional (LDBEN) e pela Base Nacional Comum Curricular (BNCC). Assim, a grade curricular educacional do nosso país, é repleta de disciplinas que objetivam à formação humana, porém, deixa uma lacuna quando não inclui no seu corpo o ensino da Lei maior do nosso país, a Constituição Federal e os demais direitos que se fazem essencial.

Para atender a tais finalidades no âmbito da educação escolar, a Carta Constitucional, no Artigo 2io, já reconhece a necessidade de que sejam "fixados conteúdos mínimos para o ensino fundamental, de maneira a assegurar formação básica comum e respeito aos valores culturais e artísticos, nacionais e regionais”. Além disso, o artigo 2I 4 da Constituição Federal/1988 estabelece as diretrizes para a educação, bem como, prevê a integração do 
poder público nas diferentes esferas, com o intuito de erradicar o analfabetismo, universalizar o atendimento escolar, melhorar a qualidade de ensino, garantir a promoção humanística e a formação para o trabalho.

De forma específica, a Lei das diretrizes e bases da educação nacional, Lei $\mathrm{n}^{\mathrm{o}}$ 9.394/96, estabelece os princípios e objetivos da educação básica a formação para o exercício da cidadania, conforme disposto (Constituição Federal, I988):

Art. 2o A educação, dever da família e do Estado, inspirada nos princípios de liberdade e nos ideais de solidariedade humana, tem por finalidade o pleno desenvolvimento do educando, seu preparo para o exercício da cidadania e sua qualificação para o trabalho.

Art. 22. A educação básica tem por finalidades desenvolver o educando, assegurarlhe a formação comum indispensável para o exercício da cidadania e fornecer-lhe meios para progredir no trabalho e em estudos posteriores.

É dentro dessa legislação que os parâmetros de escolhas das matérias e das ideologias de ensino são adotados, dessa forma, a implementação de matérias jurídicas faz-se essencial, uma vez que matérias como direito constitucional tem uma enorme relevância para a formação cidadã além de trazer consigo discussões que envolvem outros ramos essenciais do direito, como exposto brilhantemente por Tavares (2013, p. 79):

O Direito Constitucional costuma ser inserido como ramo do Direito Público, juntamente com o Direito Administrativo, Internacional, Criminal, Tributário e Processual. Essa ideia, contudo, não pode mais prosperar, na medida exata em que a Constituição passou a ocupar um papel central para todos os chamados "ramos" do Direito, sejam "matérias" públicas ou privadas. [...] Na realidade, portanto, o Direito Constitucional é a base que oferece sustentação a todos demais "direitos" disciplinados, no Brasil, por leis (leis complementares, ordinárias, delegadas), medidas provisórias e decretos. Portanto, tem-se o Direito Constitucional como a base, o fundamento dos demais "ramos" (melhor seria falar em "Direitos"), seja qual for a repartição que se queira (ou não) realizar entre esses "Direitos". O Direito Constitucional não poderia estar contido, portanto, em um dos clássicos "ramos" do Direito, pois lhes é superior, englobante e serve de fundamento de validade a todos.

O exercício da cidadania de forma específica na educação, faz-se necessário para que o cidadão possa conhecer a estrutura e funcionamento do Estado. Ter acesso a informações jurídicas já no ensino regular seria de relevante significado para o cidadão, no sentido de contribuir para o pleno exercício desse direito, e para instruir melhor as pessoas, que estariam mais bem preparadas para lidar com situações rotineiras que envolvem questões ligadas ao Direito, já que o direito faz parte da vida de todo cidadão. Também contribuiria para o crescimento intelectual e humanístico dos estudantes, ampliando o conhecimento 
de direitos e incentivando a luta pela justiça além da própria capacitação profissional para áreas que já exigem saberes jurídicos pós nível médio.

Somado a isso, e considerando a complexidade da vida em sociedade nos tempos modernos, é essencial que nossos jovens tenham, ao menos, noções básicas de seus direitos e deveres como instrumento de emancipação e exercício da cidadania. Não é mais possível sustentar que tão importantes conhecimentos estejam restritos àqueles que fazem curso superior voltado para essa área. Uma das disciplinas que mais se manifesta no dia a dia das pessoas e não pode ser um mistério, ou pior, um mecanismo de aproveitamento daqueles que detém o conhecimento, sobre aqueles que não o possuem.

A nossa Lei de Introdução às normas do Direito Brasileiro (LINDB) é clara em seu artigo $3^{\circ}$ ao dizer "Ninguém se escusa de cumprir a lei, alegando que não a conhece ", em contrapartida, se a educação é dever do estado (art. 205, CRFB), e o mesmo estado obriga o conhecimento de todos a respeito da legislação (art. $3^{\circ}$, LINDB), é natural a conclusão de que o estudo do Direito, ainda que básico, é direito fundamental de todos e dever do Estado. Se é direito fundamental, não pode estar restrito ao ambiente universitário com público restrito. É também fundamental que esteja presente na formação básica do brasileiro, ou seja, nas escolas, nas grades de ensino médio. Desse modo, a importância dos componentes curriculares pode ser compreendida pela observação de Marisa Vorraber Costa (Educação Popular Hoje, 1998, p. 4I).

O currículo e seus componentes constituem um conjunto articulado e normatizado de saberes, regidos por uma determinada ordem, estabelecida em uma arena em que estão em luta visões de mundo e onde se produzem, elegem e transmitem representações, narrativas, significados sobre as coisas e seres do mundo.

Desse modo, seria de extrema relevância a inclusão de noções de Direito no Ensino Médio, tendo como finalidade o conhecimento do Direito para a vida social, política, cultural, econômica e profissional, capacitando os alunos para o pleno exercício da cidadania em todas as esferas das relações humanas, estabelecidas em sociedade. Ferreira (2007, p. 15) aponta que:

Constitui-se, portanto, um desafio para todos aqueles que lutam por uma sociedade justa ir além do processo ensino-aprendizagem de conteúdos reservados a cada nível e modalidade de ensino. Assim, o projeto político pedagógico da escola tem suas bases num projeto social mais amplo, cujo ponto central é sempre o respeito à dignidade do ser humano. 
Portando, é importante que a juventude saiba dos seus direitos, previstos no ornamento jurídico brasileiro que deve ser parcialmente estudada no Ensino Médio, para que, futuramente, exerçam sua cidadania com propriedade e tenham discernimento para exercer com plenitude seus direitos.

\section{OBJETIVOS E FINALIDADES DA BASE NACIONAL COMUM CURRICULAR JUNTO À LEI DE DIRETRIZES BÁSICAS DE ENSINO}

A Base Nacional Comum Curricular (BNCC) tem como sua proposta considerar três grandes frentes: o desenvolvimento do protagonismo dos estudantes e de seu projeto de vida, por meio da escolha orientada do que querem estudar; a valorização da aprendizagem, com a ampliação da carga horária de estudos; e a garantia de direitos de aprendizagem comuns a todos os jovens, com a definição do que é essencial nos currículos a partir da BNCC.

A Base Nacional de ensino deixa nítido em seu portal e publicações seus critérios para estabelecer matérias bases, o primeiro, já antecipado pela Constituição, estabelece a relação entre o que é básico-comum e o que é diverso em matéria curricular: as competências e diretrizes são comuns, os currículos são diversos (cada instituição tem autonomia). O segundo se refere ao foco do currículo, ao dizer que os conteúdos curriculares estão a serviço do desenvolvimento de competências e das aprendizagens essenciais, e não apenas dos conteúdos mínimos a ser ensinados. Expresso em seu portal, a Base Nacional elenca sua linha de competência por Mendonça Filho, ao tempo, Ministro do Estado da Educação (BNCC,2018,p. II)

r) Valorizar e utilizar os conhecimentos historicamente construídos sobre o mundo físico, social, cultural e digital para entender e explicar a realidade, continuar aprendendo e colaborar para a construção de uma sociedade justa, democrática e inclusiva.

2) Exercitar a curiosidade intelectual e recorrer à abordagem própria das ciências, incluindo a investigação, a reflexão, a análise crítica, a imaginação e a criatividade, para investigar causas, elaborar e testar hipóteses, formular e resolver problemas e criar soluções (inclusive tecnológicas) com base nos conhecimentos das diferentes áreas.

3) Valorizar e fruir as diversas manifestações artísticas e culturais, das locais às mundiais, e também participar de práticas diversificadas da produção artísticocultural. 
4) Utilizar diferentes linguagens - verbal (oral ou visual-motora, como Libras, e escrita), corporal, visual, sonora e digital -, bem como conhecimentos das linguagens artística, matemática e científica, para se expressar e partilhar informações, experiências, ideias e sentimentos em diferentes contextos e produzir sentidos que levem ao entendimento mútuo.

5) Compreender, utilizar e criar tecnologias digitais de informação e comunicação de forma crítica, significativa, reflexiva e ética nas diversas práticas sociais (incluindo as escolares) para se comunicar, acessar e disseminar informações, produzir conhecimentos, resolver problemas e exercer protagonismo e autoria na vida pessoal e coletiva.

6) Valorizar a diversidade de saberes e vivências culturais e apropriar-se de conhecimentos e experiências que lhe possibilitem entender as relações próprias do mundo do trabalho e fazer escolhas alinhadas ao exercício da cidadania e ao seu projeto de vida, com liberdade, autonomia, consciência crítica e responsabilidade.

7) Argumentar combase em fatos, dados e informações confiáveis, para formular, negociar e defender ideias, pontos de vista e decisões comuns que respeitem e promovam os direitos humanos, a consciência socioambiental e o consumo iresponsável em âmbito local, regional e global, com posicionamento ético em relação ao cuidado de si mesmo, dos outros e do planeta.

8) Conhecer-se, apreciar-se e cuidar de sua saúde física e emocional, compreendendo-se na diversidade humana e reconhecendo suas emoções e as dos outros, com autocrítica e capacidade para lidar com elas.

9) Exercitar a empatia, o diálogo, a resolução de conflitos e a cooperação, fazendose respeitar e promovendo o respeito ao outro e aos direitos humanos, com acolhimento e valorização da diversidade de indivíduos e de grupos sociais, seus saberes, identidades, culturas e potencialidades, sem preconceitos de qualquer natureza.

Io) Agir pessoal e coletivamente com autonomia, responsabilidade, flexibilidade, resiliência e determinação, tomando decisões com base em princípios éticos, democráticos, inclusivos, sustentáveis e solidários.

Nessa perspectiva de rotular os aspectos que estabelecem as matérias básicas, agregase expor o que está previsto no artigo 35 da lei no 9.394 referente as diretrizes básicas por Fernando Henrique Cardoso (1996, p. 12):

Art. 35. O ensino médio, etapa final da educação básica, com duração mínima de três anos, terá como finalidades:

I - a consolidação e o aprofundamento dos conhecimentos adquiridos no ensino fundamental, possibilitando o prosseguimento de estudos; 
II - a preparação básica para o trabalho e a cidadania do educando, para continuar aprendendo, de modo a ser capaz de se adaptar com flexibilidade a novas condições de ocupação ou aperfeiçoamento posteriores;

III - o aprimoramento do educando como pessoa humana, incluindo a formação ética e o desenvolvimento da autonomia intelectual e do pensamento crítico;

$\mathrm{V}$ - A compreensão dos fundamentos científico-tecnológicos dos processos produtivos, relacionando a teoria com a prática, no ensino de cada disciplina.

Seguindo essas diretrizes do BNCC e da LDB, observa-se os parâmetros que baseiam o ensino médio, servindo como fundamentos para a própria legislação, o ensino médio apresenta-se com o propósito de alcançar o desenvolvimento humano, técnico, ético, cognitivo e social dos estudantes e seguindo tais parâmetros amparados legalmente, a educação brasileira não se limita a um rol taxativo de matérias, em contrapartida adota uma linha no desenvolvimento do ensino, e dentro desses parâmetros, a implementação de matérias jurídicas é um dos viés para o desenvolvimento educacional da sociedade, tendo em vista a relevância social das matérias no convívio social e no exercício da cidadania.

Ademais, as matérias básicas do direito são expressivas para o pleno exercício da cidadania, desse modo, demonstra a relevância dessa implementação básica de ensino tendo em vista as exigências educacionais da BNCC e LDB que se enquadram com as matérias jurídicas, pautando-se assim, em leis que asseguram a: celeridade, cidadania, direitos e deveres.

Sob esse viés, as ideologias adotadas para elaborar a grade curricular do ensino nacional, o qual aborda a necessidade de: "fixar conteúdos mínimos para o ensino de maneira a assegurar formação básica comum e o respeito aos valores culturais e artísticos, nacionais e regionais para o exercício da cidadania", desse modo, a implementação de matérias jurídicas em níveis inferiores a graduação segue os parâmetros da legais.

\section{A EDUCAÇÃO TÉCNICA DE NÍVEL MÉDIO}

Temos assistido nos últimos anos à implementação de políticas públicas de formação docente que têm assumido a centralidade da competência individual, concentrando-a na expansão e qualidade das instituições de nível superior seguindo a referência para a formação e para a avaliação de professores e alunos sem a preocupação de capacitá-los com um ensino técnico caso tome caminhos diversos ao da graduação. 
Somado a isso, ao longo dos últimos anos consolidou-se a imagem, a qual foi potencializada durante o governo Fernando Henrique Cardoso, de que o estado só financiaria a reforma e adaptação de ensino através do PROEP (Programa de Espação da Educação Profissional) se houvesse a separação formal dos currículos do ensino médio e do ensino técnico. $\mathrm{Na}$ verdade, as orientações do PROEP, foram mais além, pois em prática os projetos apresentados com vistas ao financiamento da reforma do ensino médio, sequer podiam explicitar ações relacionadas com o ensino técnico, sob pena do próprio projeto ser rechaçado como um todo, sendo que essa decisão era claramente atribuída ao Banco Internacional do Desenvolvimento (BID) pelos que estavam no MEC naquele momento, ano de 1998.

Durante a vigência de Fernando Henrique Cardoso no governo, esse instrumento legal sofreu grande resistência e críticas provenientes dos mais variados setores, como dos sindicatos de docentes e técnico administrativos vinculados a educação permanente, da comunidade científica, principalmente dos setores que atuam na esfera da educação e trabalho, dos docentes da rede federal de educação tecnológica, que mais tarde teriam a primeira iniciativa de adaptar cursos técnicos junto ao ensino médio. A união dessas forças, durante o atual governo, se consolidou no sentido de promover mudanças no ensino, dentre as quais, a já mencionada revogação do Decreto no $2.208 / 97$, materializada na edição do Decreto no 5.154/2004, que assegura em seu artigo 36 (BRASIL, 2004):

“Art. 36. O ensino médio observará o disposto na seção I deste capítulo e as seguintes diretrizes:

§ 2. O ensino médio, atendida a formação geral do educando, poderá preparar para o exercício de profissões técnicas”

O Ensino Integrado na Vigência do Decreto no 5.154 de 2004 fez alterações na lei de Diretrizes Básicas da Educação Nacional (lei 9.394/96), e por vez estabeleceu a possibilidade de integrar novamente o ensino médio à educação profissional técnica além de manter as ofertas dos cursos técnicos concomitantes e subsequentes, além de definir os modelos de articulação (BRASIL, 2004).

§ Iํ A articulação entre a educação profissional técnica de nível médio e o ensino médio dar-se-á de forma:

I - Integrada, oferecida somente a quem já tenha concluído o ensino fundamental, sendo o curso planejado de modo a conduzir o aluno à habilitação profissional técnica de nível médio, na mesma instituição de ensino, contando com matrícula única para cada aluno; 
II - Concomitante, oferecida somente a quem já tenha concluído o ensino fundamental ou estejam cursando o ensino médio, na qual a complementaridade entre a educação profissional técnica de nível médio e o ensino médio pressupõe a existência de matrículas distintas para cada curso, podendo ocorrer:

a) na mesma instituição de ensino, aproveitando-se as oportunidades educacionais disponíveis;

b) em instituições de ensino distintas, aproveitando-se as oportunidades educacionais disponíveis; ou

c) em instituições de ensino distintas, mediante convênios de intercomplementar, visando o planejamento e o desenvolvimento de projetos pedagógicos unificados;

III - Subsequente, oferecida somente a quem já tenha concluído o ensino médio.

A Proposta surgiu revolucionando os parâmetros nacionais da educação, uma vez que rompe os paradigmas históricos de uma educação estática e limitada a um rol taxativo de disciplinas inflexíveis. Sob essa perspectiva, a implementação de um ensino profissionalizante em momentos anteriores a graduação pode facilitar o desenvolvimento social das novas gerações, considerando o atual momento de crise no país, uma capacitação técnica não se limita a beneficiar exclusivamente os alunos participantes, mas também o mercado de trabalho de modo que, havendo satisfação na área cursada o aluno tendencialmente segue carreira, sendo na iniciativa privada ou da graduação.

Somado a isso, os dados divulgados pelo Instituto Nacional de Estudos e Pesquisas (INEP) citam que a maioria dos cidadãos brasileiros não prosseguem os estudos em nível superior, e atuam profissionalmente com um nível de escolarização que não ultrapassa a educação básica, dessa forma, agregar o Técnico ao Ensino Médio junto a sua ideologia de ensino, diferenciada da duração do nível médio regular, é essencial para desenvolver a capacitação profissional dentro de um estágio supervisionado. Essa medida certamente fortalece o caráter profissionalizante tanto no discente como na Instituição, até porque é o estágio supervisionado que articula e estreita a relação entre o mercado de trabalho com a instituição e o educando.

Por um lado, desde 1996, é ciente que a Lei de Diretrizes e Bases da Educação Nacional, Lei no 9.394/96 - LDBEN, não trata da separação entre ensino básico e técnico. Ao contrário, o capítulo III que passou a abordar em seu artigo 40: (BRASIL, 1996)

\footnotetext{
"Art. 40 A educação profissional será desenvolvida em articulação com o ensino regular ou por diferentes estratégias de educação continuada, em instituições especializadas ou no ambiente de trabalho."
} 
Essa ressente alteração no sistema educacional trás consigo a demonstração que, conhecimentos além dos já pré-estabelecidos pela Base Nacional Comum Curricular são essenciais para desenvolvimento educacional, além de atingir diretamente a qualificação de seus profissionais e auxiliar os discentes na decisão de seguir carreira na pós-graduação ou partir para a iniciativa privada. Em contrapartida, entre os diversos cursos técnicos já disponíveis junto ou isolado a grade do ensino médio, percebe-se uma escassez de implementação do ensino jurídico.

Por esse fato, destaca-se as diversas vezes em que instituições de ensino tomaram iniciativas de implementar esse ensino sofrendo uma grande repressão de entidades, um exemplo disso é o Instituto Federal do Paraná que implementou o Técnico em Serviços Jurídicos que a princípio sofreu repressão da $O A B$, que sentiu-se prejudicada, por entender que seu seguimento de estudo não é adequado para níveis inferiores ao da graduação, litigio o qual foi acatado pelo CNE (Conselho Nacional de Educação) que reformulou a ideologia desse curso técnico, limitando sua área de atuação e capacitação somente para serviços de atividades técnicas administrativas em órgão do estado ou assemelhados como: Delegacias, Fórum, Ministérios, Cartórios entre outros, dessa forma, os técnicos são capacitados para um serviço que auxiliam sua área de atuação de forma limitada.

Posto isso, segundo toda a legislação destinada a educação e pelas ideologias de ensino usadas na elaboração das diretrizes básicas, o um curso técnico voltado para os conhecimentos jurídicos é relevante para o desenvolvimento educacional. Apesar da complexidade da área de atuação e pelo pouco reconhecimento da $\mathrm{OAB}$, a implementação desse curso transborda os limites educacionais, uma vez que os conhecimentos jurídicos são essenciais para uma vida digna, tornando dever do estado facilitar o acesso a essa informação, como afirma Alfred Marshall em sua obra (Princípios de Economia, I89o, p.ı)

\footnotetext{
"A educação está relacionada diretamente com a cidadania, e quando o estado garante que todos serão educados, este tem em mente, sem sobra de dúvidas, as exigências e a natureza da cidadania. Está tentando estimular o desenvolvimento de cidadãos em formação".
}

\section{CONTEÚdOS JURÍdICOS BÁSICOS PARA A FORMAÇÃO CIDADÃ NA EDUCAÇÃO BÁSICA}

Atualmente, é notório observar que a maioria dos cidadãos brasileiros desconhecem a estrutura do estado ou parte de seus direitos ou obrigações. Nessa perspectiva, a escassez de conteúdos jurídicos na educação brasileira cria uma contradição no próprio ornamento 
jurídico, o qual assegura ser dever do estado proporcionar a educação para o exercício da plena cidadania.

Partindo do princípio de que o homem se constitui interagindo-se com o meio social em que vive, de forma que os avanços tecnológicos e científicos nas diversas áreas do saber, de maneira rápida, provocam mudanças significativas na sociedade, tornando assim imperativo inserir o indivíduo nessa sociedade complexa, fazendo com que o indivíduo intervenha e transforme a sociedade em que faz parte.

A escola tem como sua principal tarefa, preparar o indivíduo para o convívio social, entretanto o que se tem observado é uma política excludente. É notório que a improficiência das pessoas, as mantêm numa posição de passividade, frente às questões políticas e socioeconômicas, pois quem detém as informações, detém o poder, podendo então exigir seus direitos como assegurava Nietzsche "Todo conhecimento implica poder.” Friedrich Nietzsche; na obra "Assim falava Zaratustra”. Somado a isso, se a função da escola é formar cidadãos, e se ser cidadão é, entre outros termos, ter direitos e obrigações igualitariamente perante os outros, torna-se essencial que o conhecimento sobre quais são os direitos e obrigações do cidadão seja efetivamente ensinado nas instituições de ensino básico.

Sob essa linha, Henry Greyson Shue, filosofo americano, e professor de Política e Relações internacionais da Universidade da Oxford, vem influenciando organizações mundiais como OMS (Organização Mundial da Saúde) com a ideologia de sua obra: Basic Rights, a qual preconiza Henry Shue (1980, p. 138):

[...] Há alguns direitos que devem ser satisfeitos antes de quais quer outros, a saber, os chamados direitos básicos. Eles são os direitos à segurança, subsistência e liberdade. Tais direitos seriam precondições para os demais, pois sem eles, o cumprimento dos outros direitos seria impossível. Eles asseguram algumas necessidades básicas fornecendo uma proteção mínima contra o total desamparo de modo a proteger a população vulnerável contra ameaças devastadoras.

Considerando que o aspecto da educação jurídica ser igualitária em todos os lugares, a ideologia de Henry Shue deve vale-se para definir um rol de direitos essenciais que possa prevalecer preconizando os demais. Com isto, a possibilidade de implementação curricular se embasa em aspectos conceituais de Henry. Isso por que tais direitos são definidos como necessários para o exercício dos demais direitos naturais.

Sem uma hierarquia de normas, a lei pátria (Constituição) de uma nação deve sempre prevalecer, dessa forma, para efeitos de aplicação o Direito Constitucional é 
imprescindível nesse projeto de implementação por ser o ramo do direito que trata das normas constitucionais, sendo estas as que se encontram no ápice da pirâmide normativa, as leis supremas de um Estado.

Tal conceituação se faz necessária para compreendermos que o direito constitucional é uma junção de características de forma que ao mesmo tempo que regula as relações entre particulares, esboça a soberania do estado orientando as relações estre este e aqueles, adentrando a seara do direito público, sempre respeitando os princípios consagrados na Carta Magna.

A Constituição Federal de 1988 teve uma reformulação dos valores da nossa sociedade, incluindo em seus ditames matérias antes exclusivas do direito Civil além de fazer suas próprias referencias Constitucionais estabelecendo as diretrizes para a educação, bem como, prevê a integração do poder público nas diferentes esferas, com diversos intuitos (Constituição Federal, 1988, p.64)

Art. 214. A lei estabelecerá o plano nacional de educação, de duração decenal, com o objetivo de articular o sistema nacional de educação em regime de colaboração e definir diretrizes, objetivos, metas e estratégias de implementação para assegurar a manutenção e desenvolvimento do ensino em seus diversos níveis, etapas e modalidades por meio de ações integradas dos poderes públicos das diferentes esferas federativas que conduzam a:

I - Erradicação do analfabetismo;

II - Universalização do atendimento escolar;

III - melhoria da qualidade do ensino;

IV - Formação para o trabalho;

V - Promoção humanística, científica e tecnológica do País.

VI - Estabelecimento de meta de aplicação de recursos públicos em educação como proporção do produto interno bruto

Nesse contexto, outro ramo essencial para a implementação é o próprio direito Civil por tratar do conjunto de normas e regulamentos voltado aos direitos e deveres das pessoas, de seus bens além de suas relações no âmbito privado. Presente no cotidiano de todas as pessoas, o Direito Civil é provavelmente a área mais complexa e extensa do direito do Brasil, abordando todas as questões jurídicas de pessoas naturais e físicas na esfera privada.

Podendo ser apresentado como sinônimo de direito privado, o Direito Civil pode ser descrito como o "direito do cidadão", que rege as condutas das pessoas na vida em sociedade, portanto, por lidar com questões relacionadas à interação entre pessoas físicas e 
jurídicas em questões particulares e com as relações de posse de bens, do direito das empresas, da família e das sucessões esse ramo do direito torna-se imprescindível para o foco de implementação do projeto já que trata de um direito bem exigido no exercício da cidadania.

Pautando-se em leis que coadunam com os mesmos pensamentos, celeridade, cidadania, direitos e deveres, observa-se que através de Noções Básicas de Direito na esfera Constitucional - Constituição da República Federativa do Brasil - 1988, e do Código Civil Brasileiro - Lei 10.406/2002 -evidencia-se que para o foco da implementação do projeto, esses ramos do direito, denominadas básicas para exercício da cidadania.

Somado a isso, as tratativas de conteúdo do Direito constitucional e civil são as que mais se compatibilizam com a realidade vivenciada do público-alvo do projeto, de forma que não desfavoreça outros ramos de direito, mas sim priorize um rol de conteúdos essenciais para evolução da educação cidadã, desta forma, a ideia é dar condições ao sujeito a pleitear seus direitos e conhecer seus deveres, assim como a prática de atos de cidadania.

\section{CONCLUSÃO}

Defendendo a proposta de inclusão do ensino jurídico na grade curricular do ensino regular a pesquisa versou sobre o ensino técnico jurídico. Nessa perspectiva, ao longo deste trabalho evidenciou-se a importância e a necessidade de as informações jurídicas serem ministradas nas escolas regulares, com intuito de contribuir para a formação da cidadania, o preparo para a vida em sociedade além da capacitação profissional, uma vez que no Brasil a maior parte da população não prossegue na graduação para começar sua jornada de trabalho.

A implementação também contribuiria para o crescimento intelectual e humanístico dos estudantes, ampliando o conhecimento de direitos e incentivando a luta pela justiça. Com isso, em longo prazo, há de se ter uma formação cultural jurídica, de suma importância para um país que busca crescimento em escalas internacionais. Nesse viés, instrução jurídica mesmo que num nível básico seria imprescindível para o exercício da cidadania, para nortear as condutas de ordem prática que permeiam a vida do cidadão Por fim, destacou-se o papel do cidadão, da família e do Estado em educar, além de seu aparo legal pelas legislações vigentes, inclusive no sentido de permitir noções acerca de conhecimentos jurídicos, o que contribuiria para um melhor exercício da cidadania, bem 
como uma melhor formação escolar. Desse modo, muitas pessoas deixam de lutar pelos seus direitos justamente por desconhecê-los, assim é importante que o cidadão possa conhecer seus direitos e deveres fundamentais e, nesse contexto, nada melhor que permitir essa instrução nas próprias escolas.

\section{REFERÊNCIAS}

SILVA, Rodrigo P. Escavando a verdade. Casa Publicadora Brasileira, 2008.

DOURADO, Luiz Fernandes; OLIVEIRA, João Ferreira de. Base Nacional Comum Curricular (BNCC) e os impactos nas políticas de regulação e avaliação da educação superior. A BNCC na contramão do PNE, v. 2024, p. 38-43, 2014.

FERREIRA FILHO, Manoel Gonçalves. Direitos humanos fundamentais. Saraiva Educação SA, 2005.

TAVARES, André Ramos. Curso de direito constitucional. Saraiva Educação SA, 202I. COSTA, Marisa Vorraber. Educação popular hoje: variações sobre o tema. Edicoes Loyola, 1998.

MORETTI, Vanessa Dias; DE MOURA, Manoel Oriosvaldo. A Formação Docente na Perspectiva Histórico-Cultural: em busca da superação da competência individual. Revista Psicologia Política, v. Io, n. 20, p. 345-361, 2010.

OLIVEIRA, D. R.; MIGUEL, Ana Silvia Bergantini. A nova concepção de creche pósLDB (Lei de Diretrizes e Bases da Educação Nacional-Lei no 9.394/96). Revista Fafibe, v. 5, n. 5, 2012.

GRASSL, Ms Madalena Marques Dias; DOS SANTOS, Ms Eva Aparecida; DE AZEVEDO, Leandro Villela. ENSINAR HISTÓRIA EM 2021: BNCC, LEI II645 E INCORPORAÇÃO DE TECNOLOGIAS.

FEDERAL, Senado et al. Constituição da república federativa do Brasil, 1988. 1998. 
CIVIL, Código. Lei de Introdução às normas do Direito Brasileiro. 2002. 